\title{
Evaluation of Sovodak (Sofosbuvir/Daclatasvir) Treatment Outcome in COVID-19 Patient's Compared with Kaletra (Lopinavir/ritonavir): a Randomized Clinical Trial
}

\author{
Mahdi Yadollahzadeh \\ Iran University of Medical Sciences \\ Mohana Eskandari \\ Iran University of Medical Sciences \\ Maryam Roham \\ Iran University of Medical Sciences
}

Farhad Zamani

Iran University of Medical Sciences

Azadeh Laali

Iran University of Medical Sciences

Saeed Kalantari

Iran University of Medical Sciences

Zeynab Yassin

Iran University of Medical Sciences

Erfaneh movahedi

Iran University of Medical Sciences

Mohsen Farrokhpour

Iran University of Medical Sciences

Mohamad Taghei Zeiaei

Iran University of Medical Sciences

Nader Rezaie

Iran University of Medical Sciences

Shirin Izadi

Iran University of Medical Sciences

Neda Rahimian

Iran University of Medical Sciences

Nima Moetamed

Zanjan University of Medical Sciences

Amirhossein Aliakbar

Iran University of Medical Sciences 
Fatemeh Soleimany

Iran University of Medical Sciences

Sajad Karampoor

Iran University of Medical Sciences

G. Hossein Ashrafi

Kingston University

Fahimeh Safarnezhad Tameshkel

Iran University of Medical Sciences

Mitra Ranjbar

Iran University of Medical Sciences

Mahin Jamshidi Makiani ( $\nabla$ jamshidimakiani.m@iums.ac.ir)

Iran University of Medical Sciences

Mohammad Hadi Karbalaie Niya

Iran University of Medical Sciences

\section{Research Article}

Keywords: COVID19, Treatment, Sovodak, Kaletra

Posted Date: March 17th, 2021

DOl: https://doi.org/10.21203/rs.3.rs-257762/v1

License: (c) (i) This work is licensed under a Creative Commons Attribution 4.0 International License. Read Full License 


\section{Abstract}

Background: Severe acute respiratory syndrome coronavirus 2 (SARS-CoV2) infection and treatment are significant health organizations' concerns worldwide. Although there is no proven drug license against the virus, a variety of components have under investigation. In this regard, the present study was intended to evaluate the consequences of Sovodak (Sofosbuvir/Daclatasvir) treatment in COVID-19 patients compared with Kaletra (Lopinavir/ritonavir).

Methods: This study was conducted as a randomized trial using 120 COVID19 confirmed cases between August 19th and September 19th, 2020, in which subjects were classified into two treatment groups, 58 (Sovodak group) and 54 (Kaletra group). Related statistical operations calculated significant outcomes such as survival rate and hazard ratio via SPSS v.16. Sovodak was composed of Sofosbuvir $400 \mathrm{mg}$ and Daclatasvir 60mg, and Kaletra included Lopinavir $400 \mathrm{mg}$ and ritonavir $100 \mathrm{mg}$.

Results: We observed that there was no significant difference concerning the comorbidities, death, ICU admission, remission. Besides, Kaletra had a higher rate of discharge versus Sovodak (HR=1.551 (95\% $\mathrm{Cl}=1.008-2.386), \mathrm{P}$-value=0.046), and a better outcome was observed in patients receiving

Conclusion: Sovodak compared to Kaletra by Hazard plot. Sovodak (Sofosbuvir/Daclatasvir) therapy in COVID19 cases was accompanied by a significantly higher survival rate and better outcome than Kaletra (Lopinavir/ritonavir).

\section{Introduction}

Severe acute respiratory syndrome coronavirus 2 (SARS-CoV2) was first identified in China and then spread to the rest of other countries. World Health Organization (WHO) announced a global alarm called COVID-19 for the disease [1]. The recent Situation Report (14 Dec 2020) of a total of 71,051,805 confirmed cases, 1,608,648 have died, and there are 574,969 new cases per day and 8,726 new deaths. Iran reported 1,108,269 confirmed cases and 52,196 deaths with daily new cases of 7,451 and deaths of 247 people in which it is ranked the 14th among all countries [2]. Currently, there are no licensed drug available acts against SARS-CoV2. However, there are different candidate components and drugs under clinical trials such as Atazanavir, Lopinavir/ritonavir, Remdesivir, Sofosbuvir, Favipiravir, Arbidol, Chloroquine, and Hydroxychloroquine, Immunomodulators, TNF antagonist, Anti-IL6 antibody, Intravenous immunoglobulin, Corticosteroids, Cyclosporine, Tacrolimus [3, 4]. Lopinavir/ritonavir (LPV/RTV) or Kaletra are antiretroviral protease inhibitors that have been used in the treatment of human immunodeficiency virus (HIV) since 2000 [5]. Kaletra is composed of Lopinavir/ritonavir (LPV/RTV) (400 $\mathrm{mg}$ and $100 \mathrm{mg}$, respectively). RTV is conjugated to LPV to increase its half-life [6]. LPV acts against the viral 3-chymotrypsin-like protease, and it has been used against SARS-CoV-1 and MERS-CoV viruses previously [7-9]. There have been some Kaletra administration records for COVID-19 [10] operation, and according to guidelines, it is used for severe patients [11]. Several investigations have focused on its efficacy in COVID19 patients $[12,13]$. Sofosbuvir is a clinically approved anti-hepatitis C virus (HCV) 
drug [14][14]. Sofosbuvir is a nucleotide analog that has been approved against HCV polymerase. This drug is also able to suppress positive-strand RNA viruses [15]. SARS-CoV-2 has RNA-dependent RNA polymerase (RdRp), which could inhibit by sofosbuvir [16]. Some studies have suggested that sofosbuvir may bind strongly to the enzyme SARS-CoV-2 RdRp and inhibit its function $[17,18]$. Sofosbuvir is a safe drug and has fewer side effects. It can be tolerated at a dose of $400 \mathrm{mg}$ daily over a 24-week course of treatment [19]. in Iran, Sofosbuvir is available in combination with daclatasvir (Sovodak commercial name) (doses of 400 and $60 \mathrm{mg}$, respectively) [20]. It has been used for COVID19 patients, and then trials run to evaluate its effects.

Given the COVID 19 pandemic and the absence of proven treatment, as well as the high cost of Kaletra combination therapy and its scarcity, evaluating the efficacy of drugs such as second-generation oral antivirals in the treatment of COVID 19 can be valuable. Therefore, we decided to conduct a bicentric randomized clinical trial to compare the two treatment regimens Kaletra (LPV/RTV) and the combination therapy Sovodak (Sof/Dac).

\section{Materials And Methods}

\section{Patients and setting}

In this parallel 2-arm controlled-randomized, single-center study, a total of 120 patients referred to Firoozgar hospitals affiliated to Iran University of Medical Sciences, Tehran, Iran, were taken from August 19th to September 19th, 2020. Ethics approved by the Ethical Committee of Iran University of Medical Sciences, Tehran, Iran (code: IR.IUMS.FMD.REC.1399.407).

All patients with mild to moderate disease admitted to Firoozgar hospital, Tehran, Iran, were recruited based on inclusion criteria included age more than 18 , hospitalized patients with respiratory symptom and sao2 $>90$ and diagnostic chest CT scan (mild to moderate scores), with or without Tempreture $>38$, Excluded patients were patients have hypersensitivity to the drug, pregnant or breastfeeding, using other COVID-19 related drugs, heart rate $<60 / \mathrm{min}$, having organ failure, eGFR $<50 \mathrm{~mL} / \mathrm{min}$, decreased level of consciousness, blood pressure less than $90 / 60 \mathrm{~mm} \mathrm{Hg}$, hypoxia, blood oxygen saturation less than $90 \%$, allergies to study drugs, prior COVID-19 treatment, organ failure and patients requiring mechanical ventilation at the time of hospitalization or patients with adverse reaction drugs. All medical history of patients obtained from hospital data repositories and routine visits.

Patients with underlying disease and comorbidities were included chronic lung disease, chronic liver disease, Hepatitis, Cancer, kidney disease, cardiovascular disease (CVD), congestive heart failure (CHF), Diabetes Mellitus (DM), Hypertension (HTN or HT), Immunosuppression disease, Anemia.

Sovodak was composed of Sofosbuvir $400 \mathrm{mg}$ and Daclatasvir $60 \mathrm{mg}$. Kaletra was included Lopinavir $400 \mathrm{mg}$ and ritonavir $100 \mathrm{mg}$. Two study groups set in a randomized manner by using the ABAB block was used for the patients. Patients in block A used Sovodak (SOF/DAC 400/60) (Sovodak, Fanavaran Rojan Mohaghegh Daru Co, Tehran, Iran) one tablet every 24 hours. A group was obtained 
hydroxychloroquine $400 \mathrm{mg}$ every 12 hours for the first day, then $200 \mathrm{mg}$ every 12 hours for 5 to 7 days. Group B used Kaletra (LPV/RTV 400/100) 2 tablets every 12 hours for seven days and took hydroxychloroquine $400 \mathrm{mg}$ for the first day every 12 hours. The clinical recovery analyzed the main outcome in 5 to 7 days by normalization of fever $\left(\leq 37.2^{\circ} \mathrm{C}\right)$, respiratory rate $(\leq 24 /$ minute), and oxygen saturation $(\geq 94 \%)$. All study medication was discontinued at discharge. If the hospitalized patient's condition deteriorated, drop saturation, increased respiratory rate, we change the drug or admit the patient to ICU, we define them as the failure of treatment. Abnormal lung CT scan was defined as ground glass, air bronchogram, and consolidation findings.

\section{Outcomes and laboratory monitoring}

White blood cell count (WBC), and erythrocyte sedimentation rate (ESR) was determined at baseline, at the end of the study, and during the study, if needed. Clinical recovery was defined as normalization of body temperature $\left(<37.2^{\circ} \mathrm{C}\right)$, respiratory rate $(<24 / \mathrm{min})$, and oxygen saturation $\geq 93 \%$ without supplementary oxygen therapy at room temperature. The relative improvement of radiological evidence, lesion progression, and no need for new treatment and invasive mechanical ventilation methods were also considered responses to the treatment regimens studied.

Routine hematological analysis (white blood cell count (WBC), platelet count (PLT), and hemoglobin ( $\mathrm{Hb}$ ), complete blood cell count (CBC), etc.) was performed by an automated cell counter (Sysmex K-4500, Sysmex, Japan). BS200 Auto Analyzer (Mindray, China) was used for biochemical measurements (alanine aminotransferase (ALT) and aspartate aminotransferase (AST), etc.).

\section{Statistical analysis}

SPSS v.16 was used for statistical analysis. Variables normality was determined using the K-S test. The better outcome defined as a lower hospitalization period and no need for re-health care. Fisher's exact test for categorical outcomes. The Cox Proportional Hazard analysis was carried out for adjustment of baseline characteristics. We used the Student t-test or Mann-Whitney test to compare means and medians. Values less than 0.05 were considered as statistically significant.

\section{Clinical trial Registry}

The present study approved by Iranian Registry of Clinical Trials (IRCT) (https://www.irct.ir/) at $12 / 10 / 2020$ by the code IRCT20200328046885N1. All guidelines and protocols submitted and approved by IRCT.

\section{Results}

Among all COVID-19 admitted patients, 120 patients followed up to 14 days, 112 were included in the analysis (figure 1). The rest of the study group was excluded from the analysis due to avoid length-bias and other reasons. Of them, 54 patients (48.2\%) were in the Kaletra group, and 58 patients $(51.8 \%)$ were 
in the Sovodak group. Demographic characteristics of admitted patients in each group are listed in table 1.

Underlying disease was found in 88 (78.57\%) of all patients included in two groups. No statistically significant difference was detected between the two groups regarding the evaluated characteristics. Table 2 shows comorbidity and other variables of statistical analysis.

Table 3 shows the status of the outcome in patients who obtained Sovodak and Kaletra separately. No, any significant difference was detected between the two groups concerning the evaluated outcomes. Further details were obtained in table 3.

Table 4 showed the COX hazard proportional model results in which the length stay of hospitalization was considered the outcome, and the type of treatment predictor. Our results showed the patients who used Kaletra had a higher rate of discharge according to the time of hospitalization (HR=1.551 (95\% $\mathrm{Cl}=1.008-2.386)$, P-value=0.046). The survival function plot was displayed in figure 2 .

The hazard function plot was also drawn up, and it demonstrated that the Kaletra Hazard line is above of Sovodak hazard line. This result could define the better outcome of using Sovodak compared to Kaletra in both patients with underlying disease and without (figure 3).

\section{Discussion}

Pandemic SARS-CoV2 has no proven specific therapies available other than supportive care. Various nations used different drugs included chloroquine, hydroxychloroquine, azithromycin, lopinavir-ritonavir, favipiravir, remdesivir, ribavirin, interferon, convalescent plasma, steroids, and anti-IL-6 inhibitors, due to their antiviral or anti-inflammatory features $[4,21]$.

Recent articles have claimed that combination therapy of hydroxychloroquine and Kaletra is unlikely to have any beneficial effects against COVID-19 and might even be harmful to the patients, so alternative treatments must be explored and used [22-24]. According to the studies [14, 16, 25, 26], there are no specific side effects in people using Sofosbuvir, so this drug can be used as a suitable alternative for treating patients with COVID-19.

In this regard, by the present study, we have set up a randomized trial on 112 confirmed COVID19 patients (54 were in the Kaletra group and 58 were in the Sovodak group) in a referral hospital in Tehran, Iran. We found that there was no significant difference regarding the comorbidities, death, ICU admission, remission. Additionally, Kaletra had a higher rate of discharge versus Sovodak ( $\mathrm{HR}=1.551(95 \% \mathrm{Cl}=1.008-$ 2.386), P-value=0.046), and a better outcome was observed in patients using Sovodak compared to Kaletra by Hazard plot.

Clinical trials in Iran have been performing on Sofosbuvir's efficacy alone or in combination with daclatasvir or other antivirals such as ledipasvir and velpatasvir for the treatment of COVID-19 patients (https://www.irct.ir/). Among these studies, we can name the study of Sadeghi et al. [26], which was 
performed on two groups of patients; a treatment arm receiving sofosbuvir and daclatasvir plus standard care, and a control arm receiving standard care alone. This study showed that the addition of sofosbuvir and daclatasvir to standard care significantly reduced the hospitalization duration and mortality rate compared with standard care alone. This study provides timely evidence of the efficacy of Sovodak in the treatment of COVID-19 patients during its rapid pandemic. One of this study's strengths was that all patients were treated with standard medication, and the study was not placebo-controlled. In this case, it became possible to compare patients based on the type of treatment of choice, in addition to treatment with hydroxychloroquine. Performing a placebo-controlled trial during a pandemic is a challenge. Also, due to the higher mortality probability of the present disease, a placebo-controlled trial is not recommended if left untreated.

In the study of Sadeghi et al. [13] on 66 COVID19 patients (33 in Kaletra and 33 in Sovodak groups), they have not found any increase in Kaletra's survival rate compared with Sovodak group. Interestingly, we have found significant differences in the two groups' survival rate, and Sovodak had a better outcome than Kaletra in both patients with underlying disease and without. This differences may reflect the limitation of Sadeghi et al. [13] by the sample size in which our study enrolled more than three times larger sample size versus that study. Additionally, Sadeghi et al. [13] reported Sovodak combination with standard care could reduce the hospitalization duration; in the current study, we have found that the Kaletra group had lower ICU admission, disease severity, and hospitalization duration compared with the Sovodak group; however, the better outcome was seen in Sovodak group based on Hazard function plot. Some undesirable events, such as loss of follow-up due to Iran heath policy encourage people to stay at home to follow the treatment until severe symptoms emergence [13] and death, may impact our results. Our study follow-up duration mean was 14 days but some of the cases followed 20 or fewer days. Cao et al. [27] followed 14 days for more than $85 \%$ of participants.

In a study, Kaletra (lopinavir-ritonavir) treatment in COVID19 patients had no associations with acceleration in clinical improvement, reducing mortality, and viral load depression [27]. Some studies have shown the worse effect of Kaletra + hydroxychloroquine combination therapy in COVID19 patients $[27,28]$. Compared to our study, we have found more death in the Kaletra group, although it was not significant. Moreover, a worsen outcome was shown in our studied Kaletra group compared with the Sovodak group. However, ICU admission, disease severity, and hospitalization duration were lower than those of the Sovodak group due to follow-up loss or death.

Study of Abbaspour Kasgari et al. [29] on 48 COVID19 patients divided into two groups: 24 intervention group (by the administration of $400 \mathrm{mg}$ sofosbuvir, $60 \mathrm{mg}$ daclatasvir, and $1200 \mathrm{mg}$ ribavirin) and 24 control group (standard care). They did not find hospitalization stay differences, ICU admission, and death rate between the two groups. However, they reported a significantly higher recovery rate in the sofosbuvir/daclatasvir/ribavirin arm (Gray's $P=0.033$ ). Compared to our study, the differences may due to the larger sample size, our center setting, and enrollment of patients from different provinces referred to the capital of Iran, not just local residents. 
Our study had some limitations. Viral load quantitation and its follow-up during treatment to calculate the viral shedding period are very important to estimating treatment efficiency; however, total recovery, ICU admission, and laboratory tests could illustrate it as well; however, their association was not clearly understood [27,30]. The serum concentration of each drug could help find both drugs' antiviral effect, which contains two components. In this regard, we have failed to calculate their levels due to the high costs of analysis and limited budget. Also, we have not a long-term follow-up after treatment for the participants to estimate the complete drug efficiency. Other limitations include different participant numbers and the difference in CT scan involvement findings at the baseline divided into two groups. Additionally, there was a shortage of SARS-CoV-2 PCR tests not to obtain follow-up PCR on the patients.

\section{Conclusion}

In conclusion, this large scale study proves Sovodak administration's priority by little or no side effects versus Kaletra. Sovodak might be useful in reducing the hospitalization duration and mortality rate and increasing patients' remission. These results justify the integration of sofosbuvir/daclatasvir into largescale trials leading to approval for treatment of coronavirus infection. In this regard, we have found that the overall survival rate and outcome by the Sovodak group were better than those in the Kaletra group. However, our limitations, such as viral load quantitation and long term follow-ups, need to be considered in further multi-center studies.

\section{Declarations}

\section{Ethical Approval and Consent to Participate}

All methods were carried out in accordance with the Declaration of Helsinki and informed consent was obtained from each patient. Written consent signed by each participant. This study approved by the Ethical Committee of Iran University of Medical Sciences, Tehran, Iran with ethical code IR.IUMS.FMD.REC.1399.407.

\section{Availability of data and materials}

The present study datasets used and/or analysed during the current study are available from the corresponding author on reasonable request.

\section{Conflict of interest}

All authors declare that they have no conflict of interest.

\section{Funding}

This study supported as a grant project in Iran University of Medical Sciences, Tehran, Iran by the code: 98-5-30-17579. 
Study concept and design: M. J. M., and M. R.; Clinical study and data acquisition: M. Y., M. R., A. L., S. K., Z. Y., E. M., M. F., N. R. and M. T. Z. ; Analysis and interpretation of data: N. M., M. E., A. A. and F. S.. Drafting of the manuscript: M. H. K. N., N. R. and S. K.; Critical revision of the manuscript for important intellectual content: F. Z., FST, FZ, G. H. A. and M. J. M.; Statistical analysis: N. M., S. I. and F. S.

\section{Acknowledgements}

All authors pleased to acknowledge supports of Firoozgar Hospital, Tehrsn, Iran, personnel.

Consent for publication

Not applicable.

\section{References}

1. Tabibzadeh A, Zamani F, Laali A, Esghaei M, Tameshkel FS, Keyvani H, Makiani MJ, Panahi M, Motamed N, Perumal D: SARS-CoV-2 molecular and phylogenetic analysis in COVID-19 patients: a preliminary report from Iran. Infection, Genetics and Evolution 2020:104387.

2. WHO Official Updates - Coronavirus Disease 2019 - who.int

3. Rome BN, Avorn J: Drug evaluation during the Covid-19 pandemic. New England Journal of Medicine 2020.

4. Kalil AC: Treating COVID-19-off-label drug use, compassionate use, and randomized clinical trials during pandemics. Jama 2020, 323(19):1897-1898.

5. Lu C-C, Chen M-Y, Lee W-S, Chang Y-L: Potential therapeutic agents against COVID-19: What we know so far. J Chin Med Assoc 2020, 83(6):534-536.

6. Cvetkovic RS, Goa KL: Lopinavir/ritonavir: a review of its use in the management of HIV infection. Drugs 2003, 63(8):769-802.

7. Chu C, Cheng V, Hung I, Wong M, Chan K, Chan K, Kao R, Poon L, Wong C, Guan Y: Role of lopinavir/ritonavir in the treatment of SARS: initial virological and clinical findings. Thorax 2004, 59(3):252-256.

8. Chan JF-W, Yao Y, Yeung M-L, Deng W, Bao L, Jia L, Li F, Xiao C, Gao H, Yu P: Treatment with lopinavir/ritonavir or interferon- $\beta 1 \mathrm{~b}$ improves outcome of MERS-CoV infection in a nonhuman primate model of common marmoset. The Journal of infectious diseases 2015, 212(12):1904-1913.

9. Kim UJ, Won E-J, Kee S-J, Jung S-I, Jang H-C: Case report Combination therapy with lopinavir/ritonavir, ribavirin and interferon-a for Middle East respiratory syndrome. Antiviral therapy 2016, 21:455-459.

10. Lim J, Jeon S, Shin HY, Kim MJ, Seong YM, Lee WJ, Choe KW, Kang YM, Lee B, Park SJ: Case of the Index Patient Who Caused Tertiary Transmission of COVID-19 Infection in Korea: the Application of 
Lopinavir/Ritonavir for the Treatment of COVID-19 Infected Pneumonia Monitored by Quantitative RT-PCR. J Korean Med Sci 2020, 35(6):e79-e79.

11. Zhang L, Liu Y: Potential interventions for novel coronavirus in China: A systematic review. Journal of Medical Virology, n/a(n/a).

12. Dalili N, Kashefizadeh A, Nafar M, Poorrezagholi F, Firouzan A, Samadian F, Samavat S, Ziaie S, Fatemizadeh S: Adding Colchicine to the Antiretroviral Medication-Lopinavir/Ritonavir (Kaletra) in Hospitalized Patients with Non-Severe Covid-19 Pneumonia: A Structured Summary of a Study Protocol for a Randomized Controlled Trial. Trials 2020, 21(1):1-3.

13. Sadeghi A, Asgari AA, Norouzi A, Kheiri Z, Anushirvani A, Montazeri M, Hosamirudsai H, Afhami S, Akbarpour E, Aliannejad R: Sofosbuvir and daclatasvir compared with standard of care in the treatment of patients admitted to hospital with moderate or severe coronavirus infection (COVID-19): a randomized controlled trial. Journal of Antimicrobial Chemotherapy 2020.

14. Nourian A, Khalili H: Sofosbuvir as a potential option for the treatment of COVID-19. In: Acta Biomed. vol. 91; 2020: 236-238.

15. Cheng G, Tian Y, Doehle B, Peng B, Corsa A, Lee Y-J, Gong R, Yu M, Han B, Xu S: In vitro antiviral activity and resistance profile characterization of the hepatitis $C$ virus NS5A inhibitor ledipasvir. Antimicrobial agents and chemotherapy 2016, 60(3):1847-1853.

16. Sayad B, Sobhani M, Khodarahmi R: Sofosbuvir as Repurposed Antiviral Drug Against COVID-19: Why Were We Convinced to Evaluate the Drug in a Registered/Approved Clinical Trial? Arch Med Res 2020:S0188-4409(0120)30551-30558.

17. Elfiky AA: Ribavirin, Remdesivir, Sofosbuvir, Galidesivir, and Tenofovir against SARS-CoV-2 RNA dependent RNA polymerase (RdRp): A molecular docking study. Life Sci 2020, 253:117592-117592.

18. Chien M, Anderson TK, Jockusch S, Tao C, Kumar S, Li X, Russo JJ, Kirchdoerfer RN, Ju J: Nucleotide Analogues as Inhibitors of SARS-CoV-2 Polymerase. bioRxiv 2020:2020.2003.2018.997585.

19. Ferreira AC, Reis PA, de Freitas CS, Sacramento CQ, Hoelz LVB, Bastos MM, Mattos M, Rocha N, de Azevedo Quintanilha IG, Pedrosa CdSG: Beyond members of the Flaviviridae family, sofosbuvir also inhibits chikungunya virus replication. Antimicrobial agents and chemotherapy 2019, 63(2).

20. Eslami G, Mousaviasl S, Radmanesh E, Jelvay S, Bitaraf S, Simmons B, Wentzel H, Hill A, Sadeghi A, Freeman $\mathrm{J}$ et al: The impact of sofosbuvir/daclatasvir or ribavirin in patients with severe COVID-19. Journal of Antimicrobial Chemotherapy 2020.

21. COVID A: Treatment Trial. ClinicalTrials. gov identifier: NCT04280705. Posted February 21, 2020. In.

22. Tang W, Cao Z, Han M, Wang Z, Chen J, Sun W, Wu Y, Xiao W, Liu S, Chen E et al: Hydroxychloroquine in patients with mainly mild to moderate coronavirus disease 2019: open label, randomised controlled trial. BMJ (Clinical research ed) 2020, 369:m1849.

23. Cao B, Wang Y, Wen D, Liu W, Wang J, Fan G, Ruan L, Song B, Cai Y, Wei M et al: A Trial of LopinavirRitonavir in Adults Hospitalized with Severe Covid-19. New England Journal of Medicine 2020, 382(19):1787-1799. 
24. Geleris J, Sun Y, Platt J, Zucker J, Baldwin M, Hripcsak G, Labella A, Manson DK, Kubin C, Barr RG et al: Observational Study of Hydroxychloroquine in Hospitalized Patients with Covid-19. New England Journal of Medicine 2020, 382(25):2411-2418.

25. McQuaid T, Savini C, Seyedkazemi S: Sofosbuvir, a Significant Paradigm Change in HCV Treatment. J Clin Transl Hepatol 2015, 3(1):27-35.

26. Sadeghi A, Ali Asgari A, Norouzi A, Kheiri Z, Anushirvani A, Montazeri M, Hosamirudsai H, Afhami S, Akbarpour E, Aliannejad R et al: Sofosbuvir and daclatasvir compared with standard of care in the treatment of patients admitted to hospital with moderate or severe coronavirus infection (COVID-19): a randomized controlled trial. Journal of Antimicrobial Chemotherapy 2020.

27. Tang W, Cao Z, Han M, Wang Z, Chen J, Sun W, Wu Y, Xiao W, Liu S, Chen E: Hydroxychloroquine in patients with mainly mild to moderate coronavirus disease 2019: open label, randomised controlled trial. BMJ (Clinical research ed) 2020, 369.

28. Geleris J, Sun Y, Platt J, Zucker J, Baldwin M, Hripcsak G, Labella A, Manson DK, Kubin C, Barr RG: Observational study of hydroxychloroquine in hospitalized patients with Covid-19. New England Journal of Medicine 2020.

29. Abbaspour Kasgari H, Moradi S, Shabani AM, Babamahmoodi F, Davoudi Badabi AR, Davoudi L, Alikhani A, Hedayatizadeh Omran A, Saeedi M, Merat S: Evaluation of the efficacy of sofosbuvir plus daclatasvir in combination with ribavirin for hospitalized COVID-19 patients with moderate disease compared with standard care: a single-centre, randomized controlled trial. Journal of Antimicrobial Chemotherapy 2020.

30. Joynt GM, Wu WK: Understanding COVID-19: what does viral RNA load really mean? The Lancet Infectious Diseases 2020, 20(6):635-636.

\section{Tables}

Table 1. The basic characteristics of two treatment groups of our study population. 


\begin{tabular}{|c|c|c|c|c|}
\hline & Drug & Mean & Std. Deviation & Std. Error Mean \\
\hline \multirow[t]{2}{*}{ SBP (mmHg) } & Kaletra & 113.69 & 10.62 & 1.44 \\
\hline & Sofosbuvir & 115.38 & 10.51 & 1.38 \\
\hline \multirow[t]{2}{*}{$\mathrm{DBP}(\mathrm{mmHg})$} & Kaletra & 73.43 & 8.79 & 1.19 \\
\hline & Sofosbuvir & 71.31 & 7.72 & 1.01 \\
\hline \multirow[t]{2}{*}{ Temperature $\left({ }^{\circ} \mathrm{C}\right)$} & Kaletra & 37.17 & 0.66 & 0.09 \\
\hline & Sofosbuvir & 37.15 & 0.64 & 0.08 \\
\hline \multirow[t]{2}{*}{ WBC } & Kaletra & 7.05 & 3.79 & 0.51 \\
\hline & Sofosbuvir & 7.54 & 6.54 & 0.85 \\
\hline \multirow[t]{2}{*}{ Lymphocyte count } & Kaletra & 22.41 & 12.18 & 1.65 \\
\hline & Sofosbuvir & 24.58 & 13.87 & 1.82 \\
\hline \multirow[t]{2}{*}{ PMN } & Kaletra & 77.58 & 12.18 & 1.65 \\
\hline & Sofosbuvir & 75.41 & 13.87 & 1.82 \\
\hline \multirow[t]{2}{*}{ Hemoglobin (mg/dl) } & Kaletra & 13.16 & 1.83 & 0.25 \\
\hline & Sofosbuvir & 13.11 & 2.09 & 0.27 \\
\hline \multirow[t]{2}{*}{ Platelet } & Kaletra & 205.68 & 83.67 & 11.38 \\
\hline & Sofosbuvir & 202.7 & 92.14 & 12.09 \\
\hline \multirow[t]{2}{*}{ ESR (minutes) } & Kaletra & 39.56 & 19.78 & 2.82 \\
\hline & Sofosbuvir & 44.3 & 21.44 & 2.94 \\
\hline \multirow[t]{2}{*}{ LDH (mg/dl) } & Kaletra & 541.51 & 192.57 & 30.83 \\
\hline & Sofosbuvir & 584.42 & 177.28 & 25.32 \\
\hline \multirow[t]{2}{*}{$250 \mathrm{H}$ vitD3 (mg/dl) } & Kaletra & 22.48 & 9.63 & 1.62 \\
\hline & Sofosbuvir & 22.28 & 9.32 & 1.47 \\
\hline \multirow[t]{2}{*}{ Urea (mg/dl) } & Kaletra & 37.74 & 21.76 & 2.96 \\
\hline & Sofosbuvir & 42.32 & 23.19 & 3.04 \\
\hline \multirow[t]{2}{*}{ AlkP (IU/I) } & Kaletra & 178.75 & 113.35 & 15.57 \\
\hline & Sofosbuvir & 205.02 & 218.83 & 28.73 \\
\hline Bilirubin total (mg/dl) & Kaletra & $\begin{array}{l}.95 \\
\text { age } 12 / 18\end{array}$ & 0.87 & 0.12 \\
\hline
\end{tabular}




\begin{tabular}{|lllll|} 
& Sofosbuvir & 1.14 & 1.89 & 0.25 \\
\hline Bilirubin direct (mg/dl) & Kaletra & 0.32 & 0.21 & 0.03 \\
\cline { 2 - 5 } & Sofosbuvir & 0.32 & 0.18 & 0.02 \\
\hline Albumin (mg/dl) & Kaletra & 1.40 & 1.92 & 0.28 \\
\cline { 2 - 5 } & Sofosbuvir & 1.87 & 1.89 & 0.26 \\
\hline Na (mg/dl) & Kaletra & 0.13 & 0.46 & 0.06 \\
\cline { 2 - 5 } & Sofosbuvir & 0.26 & 0.7 & 0.1 \\
\hline K (mg/dl) & Kaletra & 125.19 & 37.03 & 5.18 \\
\cline { 2 - 5 } & Sofosbuvir & 118.16 & 46.21 & 6.28 \\
\hline Ferritin (mg/dl) & Kaletra & 3.56 & 1.13 & 0.15 \\
\cline { 2 - 5 } & Sofosbuvir & 3.34 & 1.51 & 0.2 \\
\hline Days of hospitalization & Kaletra & 163.32 & 255.61 & 37.28 \\
\cline { 2 - 5 } & Sofosbuvir & 181.59 & 226.20 & 32.31 \\
\hline $\begin{array}{l}\text { SBP: systolic blood pressure; } \\
\text { nuclear; AlkP: Alkaline phosphatase; }\end{array}$ & Kaletra & 6.59 & 3.16 & 0.43 \\
\hline & Sofosbuvir & 9.19 & 8.43 & 1.1 \\
\hline
\end{tabular}

Table 2 - the basic characteristics of two treatment groups of study population. 


\begin{tabular}{|c|c|c|c|c|}
\hline \multirow[t]{2}{*}{ Variable } & \multirow[t]{2}{*}{ Category } & \multicolumn{2}{|c|}{ Percent (frequency) } & \multirow[t]{2}{*}{ P-value } \\
\hline & & Kaletra $(n=54)$ & Sovodak $(n=58)$ & \\
\hline \multirow[t]{2}{*}{ Sex } & Male & $46.3(25)$ & $43.1(25)$ & \multirow[t]{2}{*}{$0.734^{\star}$} \\
\hline & Female & $53,7(29)$ & $56.9(33)$ & \\
\hline Age (years) & Mean $\pm S D$ & $56.09 \pm 16.51$ & $58.93 \pm 14.03$ & $0.328 * \star \star$ \\
\hline BMI (Kg/m^2) & Mean \pm SD & $27.38 \pm 2.74$ & $28.08 \pm 6.22$ & $0.640 * \star \star$ \\
\hline 02 saturation (\%) & Mean \pm SD & $93.20 \pm 2.14$ & $93.47 \pm 2.34$ & $0.539 * * *$ \\
\hline $\mathrm{Cr}(\mathrm{mg} / \mathrm{dl})$ & Mean \pm SD & $1.05 \pm 0.52$ & $1.07 \pm 0.414$ & $0.800 * \star \star$ \\
\hline AST (IU/I) & Median (IQR) & $28.0(19.0)$ & $34.5(22.0)$ & 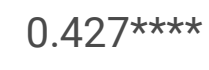 \\
\hline ALT (IU/I) & Median (IQR) & $26.0(15.0)$ & $32.5(32.0)$ & $0.064 * \star \star \star$ \\
\hline PT (s) & Mean $\pm S D$ & $11.99 \pm 4.75$ & $11.89 \pm 5.39$ & 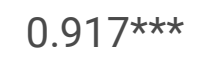 \\
\hline Hypertension & $\%(N)$ & $25.9(14)$ & $24.1(14)$ & $0.827^{\star}$ \\
\hline Diabetes mellitus & $\%(N)$ & $24.1(13)$ & $19.0(11)$ & $0.510^{\star}$ \\
\hline Immunosuppressive disease & $\%(N)$ & $1.9(1)$ & $5.2(3)$ & $0.344^{*}$ \\
\hline Chronic lung disease & $\%(N)$ & $0.0(0)$ & $6.9(4)$ & $0.119 * *$ \\
\hline Hepatitis & $\%(N)$ & $1.9(1)$ & $1.7(1)$ & $0.959 *$ \\
\hline Malignancy & $\%(N)$ & $5.6(3)$ & $15.5(9)$ & $0.089 *$ \\
\hline Kidney disease & $\%(N)$ & $5.6(3)$ & $6.9(4)$ & $0.770 *$ \\
\hline Anemia & $\%(N)$ & $1.9(1)$ & $6.9(4)$ & $0.196^{\star}$ \\
\hline Cardiovascular disease & $\%(N)$ & $16.7(9)$ & $13.8(8)$ & $0.672^{\star}$ \\
\hline Dyspnea & $\%(N)$ & $22.2(12)$ & $10.3(6)$ & $0.087^{\star}$ \\
\hline CT scan abnormality & $\%(\mathrm{~N})$ & $40.7(22)$ & $36.2(21)$ & $0.622^{\star}$ \\
\hline Comorbidity & $\%(N)$ & $14.8(8)$ & $27.6(16)$ & $0.100 *$ \\
\hline Fever & $\%(N)$ & $57.1(20)$ & $42.9(15)$ & $0.142^{\star}$ \\
\hline \multicolumn{5}{|c|}{$\begin{array}{l}\text { *chi square test was applied, } * * \text { Fisher exact test was applied, } * \star \star \\
\text { Mann-Whitney test was applied }\end{array}$} \\
\hline \multicolumn{5}{|c|}{$\begin{array}{l}\text { ALT: Alanine aminotransferase, AST Aspartate Aminotransferase; BMI: Body mass index, CT scan: } \\
\text { computerized tomography scan, Cr: creatinin, IQR: Interquartile range, PT: protrombin time, SD: } \\
\text { standard deviation }\end{array}$} \\
\hline
\end{tabular}


Table 3. the outcomes status in patients who obtained Sovodak and Kaletra.

\begin{tabular}{|lllll|}
\hline Outcome & Status & \multicolumn{2}{c|}{ Percent (frequency) } & P-value \\
\cline { 2 - 4 } & & Sovodak & Kaletra & \\
\hline \multirow{2}{*}{ Death } & Yes & $5.2(3)$ & $3.7(2)$ & $0.707 *$ \\
\cline { 2 - 4 } & No & $94.8(55)$ & $96.3(52)$ & \\
\hline \multirow{2}{*}{ ICU admission } & Yes & $10.3(6)$ & $3.7(2)$ & $0.173^{*}$ \\
\cline { 2 - 4 } & No & $89.7(52)$ & $96.3(52)$ & \\
\hline Remission & Yes & $86.2(50)$ & $87.0(47)$ & $0.897 *$ \\
\cline { 2 - 4 } & No & $13.8(8)$ & $13.0(7)$ & \\
\hline ICU: intensive care unit, *Chi square test was applied & \\
\hline
\end{tabular}

Table 4-The results of COX regression model

\begin{tabular}{|llll|}
\hline Variable & Wald & HR (Hazard ratio) & p-value \\
\hline Drug (Kaletra vs. Sovodak) & 3.99 & $1.551(1.008-2.386)$ & 0.046 \\
\hline Lung disease & 0.431 & $1.504(0.445-5.086)$ & 0.511 \\
\hline Malignancy & 0.561 & $1.276(0.674-2.417)$ & 0.454 \\
\hline Anemia & 0.182 & $0.809(0.306-2.129)$ & 0.669 \\
\hline Dyspnea & 0.534 & $0.806(0.452-1.437)$ & 0.465 \\
\hline Comorbidity & 0.039 & $1.054(0.622-1.786)$ & 0.844 \\
\hline ALT & 0.173 & $0.999(0.996-1.003)$ & 0.678 \\
\hline ALT: Alanine aminotransferase & & \\
\hline
\end{tabular}

Figures 


\section{All patients}

$$
n=120
$$

No complete data $(n=5)$, loss of follow

$$
\text { up }(n=3)
$$

$$
n=8
$$

All that enrolled in our study

\section{$\mathrm{n}=112$}

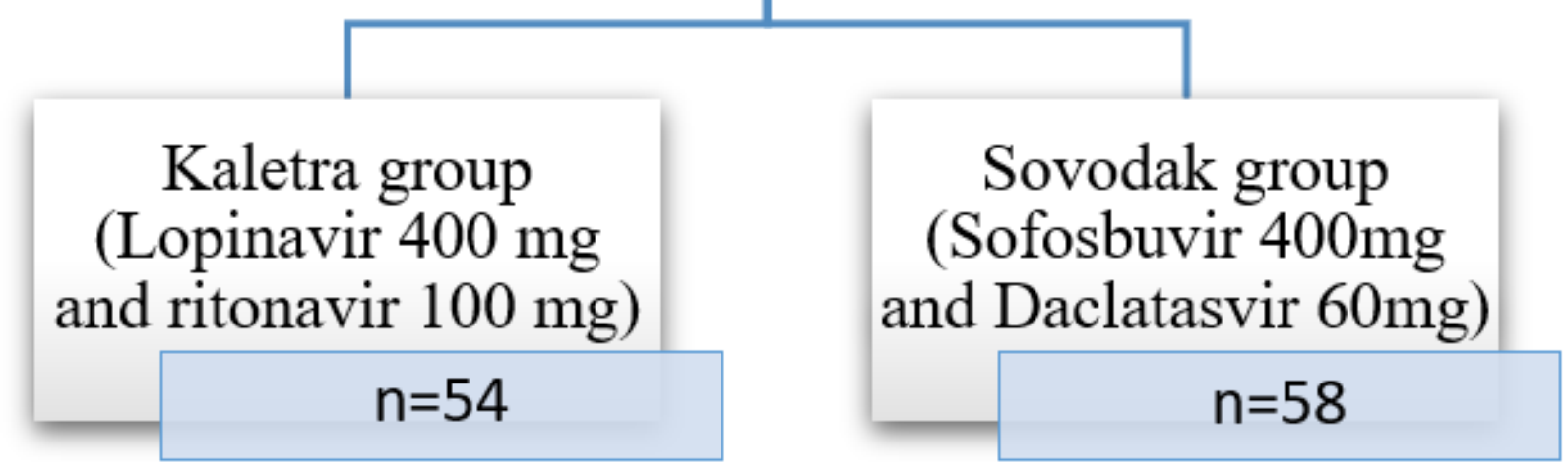

Figure 1

Flow diagram of enrolled patients. 


\section{Survival Function for patterns 1 - 2}

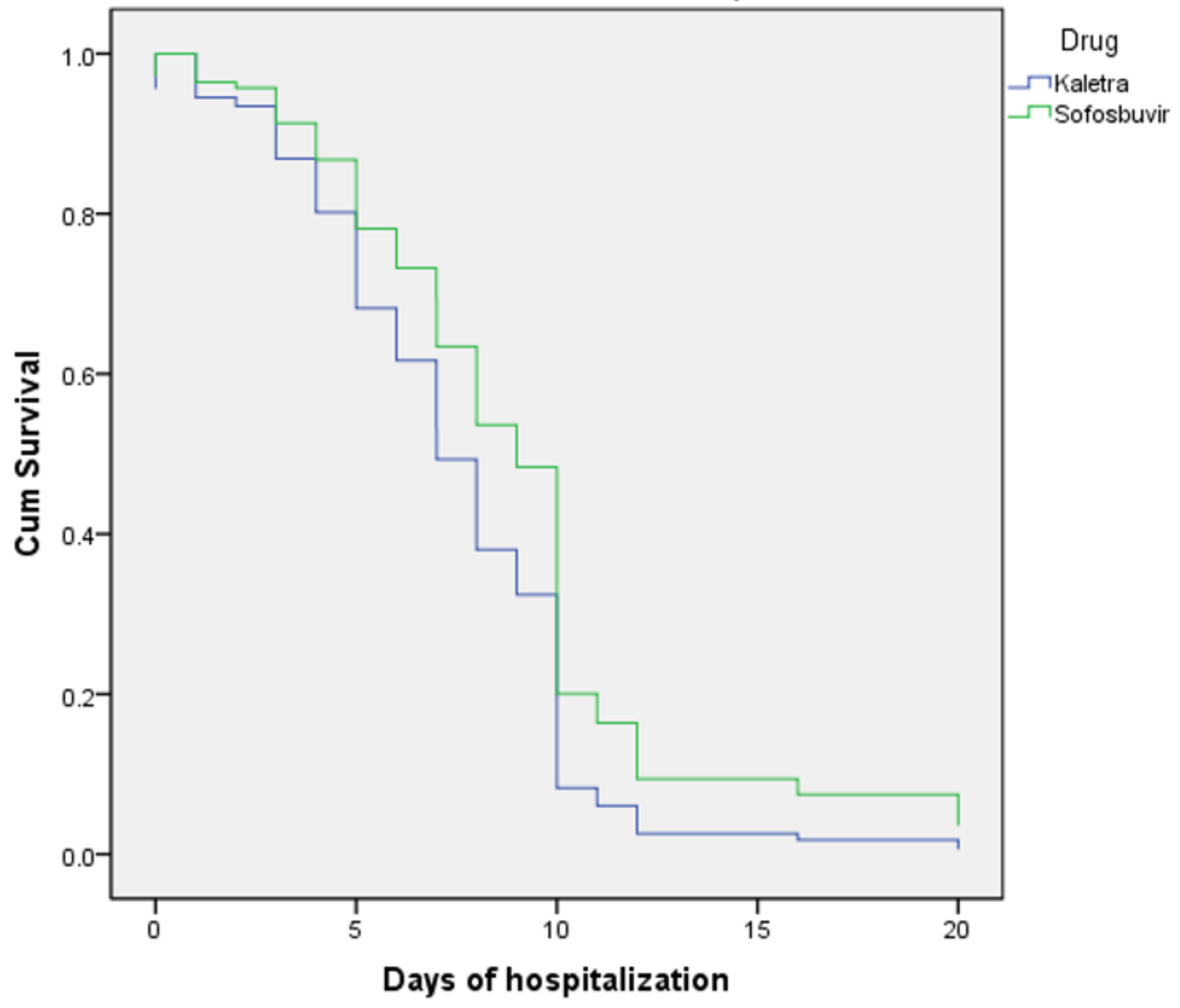

Figure 2

Survival Function plot in Cox proportional hazard model 


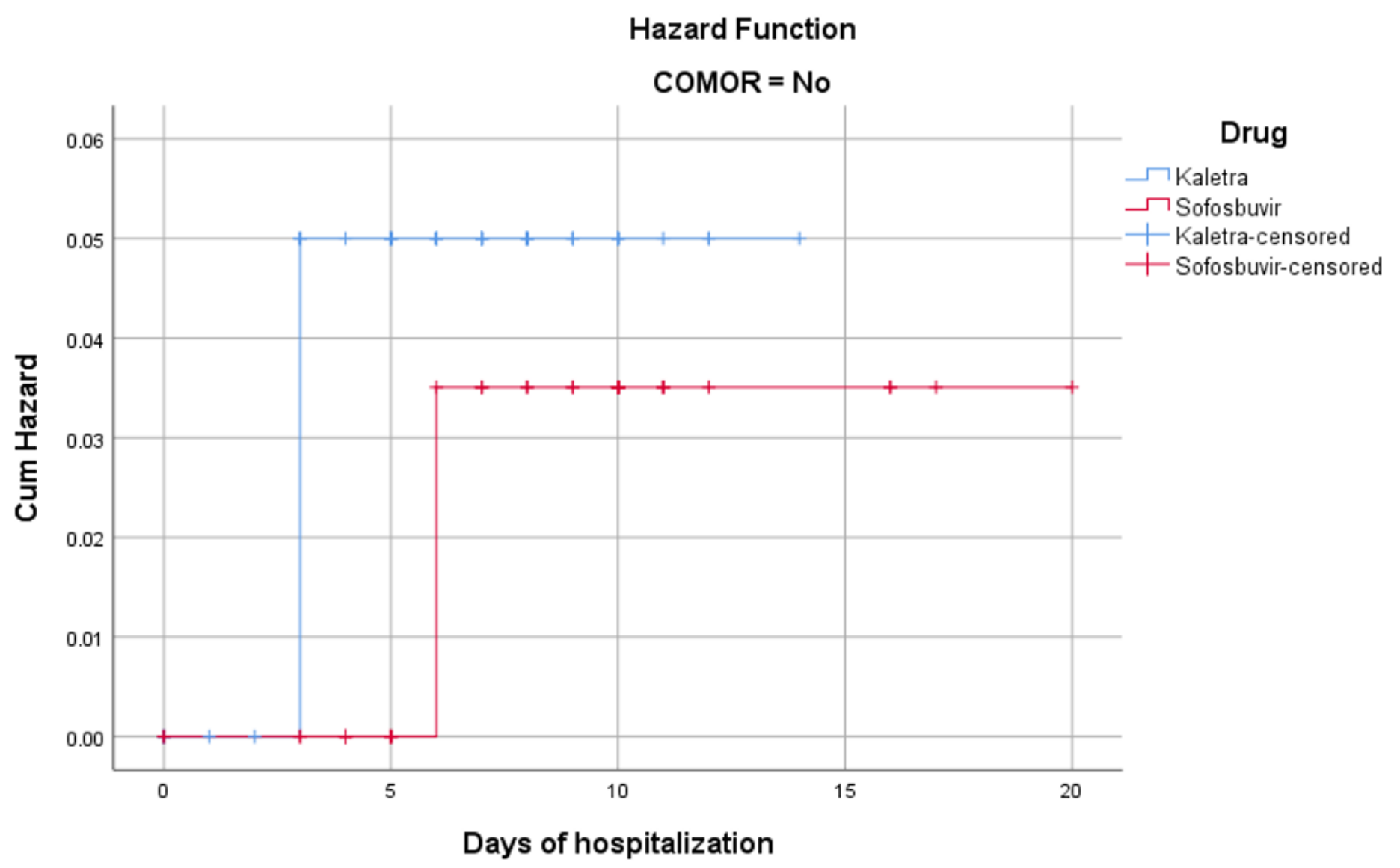

Figure 3

Hazard ratio analysis Sovodak group vs. Kaletra group. 